\title{
UM EXPERIMENTO SOBRE INTENÇÃO DE COMPRA E ATITUDE FRENTE A EMBALAGEM DE CONSUMIDORES DE COSMÉTICOS COM CERTIFICAÇÃO ECOLÓGICA
}

\author{
Laura Torres Mello ${ }^{1}$ \\ João Felipe Rammelt Sauerbronn²
}

\begin{abstract}
RESUMO
O presente trabalho tem por finalidade abordar o tema marketing ambiental como estratégia para a comercialização de cosméticos ecologicamente corretos, bem como propor e testar um modelo estatístico para analisar os efeitos das estratégias de marketing ambiental sobre as atitudes e intenção de compra do consumidor. Para isso, investigamos o impacto de um argumento de caráter ecológico sobre atitudes relativas à embalagem e à intenção de compra. Dados foram coletados através de um estudo experimental com 100 estudantes de graduação do Rio de Janeiro. Ao concluir o experimento, verificou-se que os respondentes se mostraram indiferentes à presença de argumentos ecológicos em relação à embalagem e a intenção de compra. Podemos dizer que esta pesquisa é relevante ao proporcionar à comunidade acadêmica, profissional e às empresas uma melhor compreensão acerca das atitudes dos consumidores em relação a apelos ambientais em cosméticos.
\end{abstract}

PALAVRAS-CHAVE: ATRIBUTO ECOLÓGICO. MARKETING AMBIENTAL. ATITUDE FRENTE À PROPAGANDA. INTENÇÃO DE COMPRA.

\footnotetext{
${ }^{2}$ Doutor em Administração (FGV). Mestre em Administração Pública (FGV). Graduado em Ciências Econômicas (UFRJ). Professor Adjunto do PPGA da Unigranrio.
} 


\section{VIANNAS SAPIENS}

edição especial

\section{INTRODUÇÃO}

A preocupação e o interesse por questões ecológicas e ambientais vêm se intensificando em nossa sociedade, uma vez que aumentou a quantidade de problemas resultantes da poluição causada pelas grandes indústrias e passou a ser importante a preservação de energia (CUPERSCHMIDT; TAVARES, 2001). Em função disso e do aumento de regulação por parte de agencias governamentais, muitas empresas têm mudado sua forma de produção, procurando métodos de produção mais limpos, que sejam menos poluidores, consumam menos água, energia e evitem desperdício.

Do outro lado do sistema de mercado, os consumidores têm pressionado as empresas através de suas decisões de compra e passado a se comportar de maneira consciente (DE TONI; LARENTIS; MATTIA, 2012; BORELLI; HEMAIS; DIAS; 2012).

Diversos estudos já foram feitos considerando a Responsabilidade Social Corporativa (RSC) como fonte de vantagem competitiva para as empresas (vide BURKE; LODGSON, 1996; MCWILLIAMS; SIEGEL, 2006, no Brasil, PESSOA, ET AL., 2009; NEVES; LIMA; PESSOA, 2011; SAUERBRONN; SAUERBRONN, 2011). O número de organizações que publicam relatórios de sustentabilidade e divulgam seus balanços sociais tem crescido (ETHOS, 2010). Dessa maneira, as empresas buscam comunicar aos stakeholders suas ações sociais, e melhorar a imagem corporativa frente à sociedade (MACEDO; CIPOLA; FERREIRA, 2008; RASERA; CORRÊA; SANTOS; OSWALDO, 2012).

No contexto econômico e social brasileiro, segundo Dinato (1998), os consumidores ainda possuem dificuldade em perceber os benefícios que podem ser gerados por uma gestão mais eficiente dos recursos existentes e que esse comportamento pode se tornar uma fonte importante de incentivos para processos de inovação e desenvolvimento.

O principal objetivo desta pesquisa é analisar a atitude do consumidor frente à propaganda e/ou embalagem e a sua intenção de compra frente à presença de atributo ecológico em cosméticos. Sendo o Brasil um dos maiores mercados 
mundiais de cosméticos, essa indústria e o comportamento dos consumidores desses produtos têm grande importância para o mercado e para os pesquisadores da área de marketing.

O presente trabalho está estruturado em cinco partes. Seguindo essa introdução, é apresentada uma seção com breve contextualização do mercado de cosméticos. A terceira seção traz a revisão da literatura, baseada em três áreas de pesquisa: atitudes e comportamentos, atributos e marketing ambiental.

\section{MERCADO DE COSMÉTICOS}

O consumo de cosméticos tem crescido intensamente como resposta ao aumento da variedade de produtos, ao aumento da expectativa de vida e à oferta de opções para segmentos anteriormente negligenciados, por exemplo, minorias étnicas (TAMASHIRO; MERLO; SILVEIRA, 2011). À medida que a manutenção da juventude e a estética se tornam valores sociais cada vez mais importantes e diminuem as barreiras culturais, pessoas de todas as raças, origens sociais e faixas etárias, têm consumido cada vez mais cosméticos (DELLINGHAUSEN; MONDO; COSTA, 2012). De acordo com a ABIHPEC (Associação Brasileira da Indústria de Higiene Pessoal, Perfumaria e Cosméticos) (2010), o mercado brasileiro de cosméticos é o terceiro maior do mundo, gerador não apenas de renda, mas foco estratégico dos grandes "players" (grandes empresas desenvolvedoras e produtoras de cosméticos).

O Brasil se tornou, em 2009, o maior mercado da gigante norte-americana Avon, desbancando a liderança histórica dos Estados Unidos. O Boticário, que tem 2,8 mil lojas no país, aumentou em $20 \%$ suas vendas no ano passado e atingiu a receita de $R \$ 1,25$ bilhão. A Natura cresceu $18,6 \%$ e encerrou o ano com faturamento líquido de $\mathrm{R} \$ 4,24$ bilhões.

De acordo com o Instituto Internacional de Pesquisas - Euromonitor, o crescimento do setor de cosméticos no Brasil acontece em função de i) participação crescente da mulher no mercado de trabalho; ii) utilização de tecnologia de ponta e o 
Revista das Faculdades Integradas Vianna Júnior

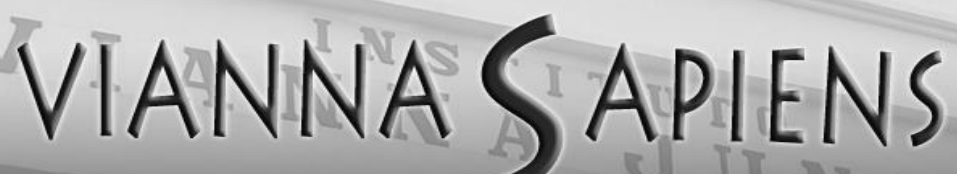

edição especial

conseqüente aumento da produtividade, favorecendo os preços praticados pelo setor, que tem aumentos menores do que os índices de preços da economia em geral; iii) lançamentos constantes de novos produtos atendendo cada vez mais às necessidades do mercado; e iv) aumento da expectativa de vida, o que traz a necessidade de conservar uma impressão de juventude.

No mercado global, o Brasil subiu para a terceira posição em 2007, ao superar a França. Dados da Euromonitor mostram que em 2008 o país detinha 8,6\% do mercado global. Mesmo com a crise econômica de 2008, a indústria de cosméticos brasileira cresceu $14,7 \%$, com uma receita de $\mathrm{R} \$ 24,97$ bilhões, segundo a ABIHPEC . Descontando a inflação no período, o crescimento foi de 11,8\%. Com a retomada da economia, as empresas esperam um avanço real de até $12 \%$ e acreditam que o Brasil tem grandes chances de superar o Japão e se transformar no segundo maior mercado mundial, atrás apenas dos Estados Unidos.

Segundo um levantamento realizado pela ABIHPEC (2010) existem no Brasil mil trezentos e sessenta e sete empresas atuando no mercado de produtos de higiene pessoal, perfumaria e cosméticos. Com relação ao tamanho dessas empresas, apenas quinze são de grande porte, com faturamento líquido de impostos acima dos $\mathrm{R} \$ 100$ milhões, o que representa $71,7 \%$ do faturamento total. Do total de empresas no País, 98,8\% são de empresas de micro, pequeno e médio porte.

O destaque dado aos produtos feitos à base de compostos naturais é uma tendência atual, sobretudo no ramo da cosmetologia (LYRIO; FERREIRA; ZUQUI; SILVA, 2011). Como conseqüência, começa a se conformar um segmento de mercado de beleza específico e mais destacado. Dados do Organic Monitor, instituto inglês de pesquisa e consultoria, concluíram que as vendas nesse mercado crescem a velocidade de US\$ 1 bilhão por ano e, atualmente, já batem na casa dos US\$7 bilhões. A liderança no consumo é dos Estados Unidos, responsável por uma fatia de US\$ 4,5 bilhões desse total. E a projeção do Organic Monitor em 2009, é de que esse mercado evolua mundialmente para US\$10 bilhões em 2010. 


\section{REFERENCIAL TEÓRICO}

\subsection{Marketing ambiental}

O Marketing ambiental é definido como a "gestão holística dos processos responsáveis por identificar, antecipar e satisfazer as necessidades dos clientes e sociedade, de forma lucrativa e sustentável". Segundo Ottman (1994), o marketing ambiental deve ter como objetivo a criação de uma imagem diferenciada da empresa, incluindo uma maior sensibilidade ambiental quanto aos atributos do produto e ao posicionamento da empresa com relação ao meio ambiente.

De acordo com Scarpinelli e Ragassi (2003), o marketing ambiental tem como objetivo promover meios que sustentem as estratégias das empresas em relação às atitudes que estas praticam na diferenciação entre seus concorrentes, é também objeto que agrega valor aos produtos e/ou serviços que tal empresa oferece ao mercado consumidor. Essa prática permite à empresa mostrar para seus stakeholders, um conjunto de processos que visam à responsabilidade social e ambiental, através de políticas de ações, projetos sociais e a promoção do equilíbrio ambiental, bem como políticas ambientais de controle e preservação do meio ambiente.

Conforme Voltolini (2005), o marketing ambiental consiste em todas as atividades desenvolvidas para gerar e facilitar quaisquer trocas, tendo a intenção de satisfazer os desejos e necessidades dos consumidores, desde que ocorram com um mínimo de impacto negativo sobre o meio ambiente. Assim, dentro do conceito de desenvolvimento sustentável, os profissionais de marketing passariam a buscar o atendimento das necessidades dos consumidores atuais e futuros, de maneira associada à promoção de idéias, comportamentos e produtos considerados ecologicamente sustentáveis.

Segundo Alves (2005), não é suficiente uma empresa dedicar-se à produção, com o mínimo impacto sobre o meio ambiente e à oferta de produtos com características ambientais se não comunicar a sua existência para os consumidores 
Revista das Faculdades Integradas Vianna Júnior

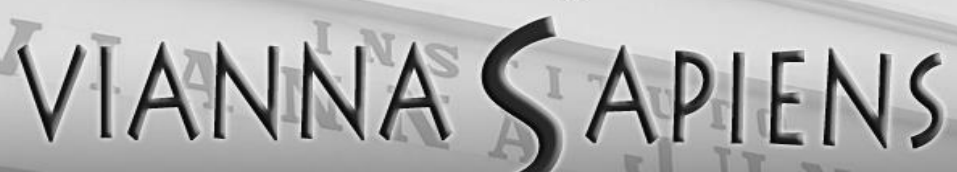

edição especial

Juiz de Fora - 2014

e para o planeta. O teor e a persuasão da informação que o processo de marketing ambiental traz apresentam-se como importantes argumentos para motivar o consumidor a agir de maneira "ambientalmente correta" na hora de escolher uma ou outra marca de produto ou serviço.

Dessa maneira, podemos definir o marketing ambiental como um conjunto de políticas e estratégias de comunicação (promoção, publicidade, relações públicas, etc.) destinadas a obter uma vantagem comparativa de diferenciação para os produtos ou serviços que oferece a empresa em relação às marcas concorrentes, conseguindo dessa forma incrementar sua participação no mercado, consolidando seu posicionamento competitivo (DIAS 2006).

\subsection{Atributos dos produtos e o atributo ecológico}

No momento em que o consumidor avalia um produto ou marca, ele se depara com várias informações sobre validade, peso, composição, país de origem, etc. Estas características descritivas do produto são denominadas atributos. Segundo Keller (1993), atributos são as características que descrevem propriamente um produto ou serviço - o que um consumidor avalia ao comprar um produto. Essas atributos podem relatar a composição física do produto, como os ingredientes necessários para a sua formulação, ou podem informar sobre características externas, como a produção ecologicamente correta ou país de origem.

Os atributos também podem ser aspectos externos de um produto que afetam a intenção de compra. Estes aspectos externos são classificados em quatro tipos: informação de preço, embalagem ou aparência do produto, imagens do usuário (que tipo de pessoa usa o produto ou serviço) e imagens de uso (onde e em que tipo de situação o produto ou serviço é usado) (KELLER, 1993).

Como apontam Pereira e Ayrosa (2004), os atributos presentes na embalagem do produto ou em anúncios podem ser utilizados por consumidores para avaliar o produto, a marca ou a empresa. Assim, a avaliação relativa ao produto, à marca ou à empresa pode afetar as atitudes e o comportamento de compra. 
Nesse trabalho, o atributo de interesse é o "atributo ecológico", no caso, uma informação de caráter ecológico presente na embalagem do produto - os selos ecológicos, que transmitem uma idéia sobre a composição física do produto e seu benefício para a saúde do usuário. Ao se deparar com argumento ecológico presente em uma embalagem, espera-se que o consumidor avalie positivamente a embalagem, a marca, e que a intenção de compra seja favorável (MINIARD, BHATLA e ROSE, 1990; MACKENZIE; LUTZ; BELCH, 1986).

O atributo ecológico deve ser entendido, como um atributo que torna o produto o menos nocivo possível ao meio ambiente, uma vez que não existem produtos que não participem da degradação ambiental. O atributo ecológico pode ser vinculado ao produto por meio de propagandas, nas embalagens, selos de certificação ambiental, entre outros (OTTMAN, 1994).

O atributo ecológico utilizado nesse estudo é um argumento que fornece informações, ou seja, pistas (conforme SZYBILO e JACOBY, 1974) sobre a produção ambientalmente correta do determinado produto. Desta forma, fornece subsídios ao consumidor para melhor avaliar o produto.

\subsection{Atitude}

Segundo Engel, Blackwell e Miniard e (2005) as atitudes representam o de que gostamos e de que não gostamos. Conservar uma atitude favorável em relação a um produto é quase sempre um pré-requisito vital para manter uma intenção de compra útil. Kotler (2000) afirma que uma atitude corresponde a avaliações, sentimentos e tendências de ação duradouros, favoráveis ou não a algum objeto ou idéia. Ou seja, as atitudes nos predispõe a gostar ou não de algo, é o que nos aproxima ou afasta dele. São predisposições aprendidas em resposta a um objeto ou a uma classe de objetos de forma consistentemente favorável ou desfavorável (SHETH; MITTAL; NEWMAN, 2001).

De acordo com Schiffman e Kanuk (2000), nossas atitudes são formadas por três principais componentes: afeto, cognição e comportamento. O componente 
Revista das Faculdades Integradas Vianna Júnior

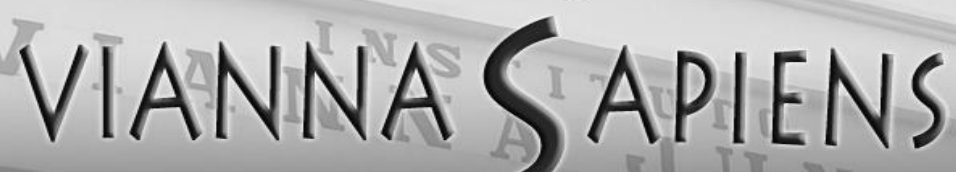

edição especial

Juiz de Fora - 2014

cognitivo representa as crenças do consumidor sobre uma marca, produto ou ação; que é baseado em um conhecimento pessoal, a experiência real, o conhecimento ou a experiência de outros ou da percepção. Esses conhecimentos e percepções resultantes, geralmente assumem a forma de crenças, ou seja, o consumidor acredita que a atitude possui vários atributos e comportamentos específicos que levarão a resultados específicos (SCHIFFMAN, KANUK, 2000).

Para Schiffman e Kanuk (2000), o componente afetivo representa os sentimentos do consumidor - por exemplo: não gosta, gosta, ou neutralidade - sobre uma marca, produto ou serviço decorrentes de crenças. Essas emoções e sentimentos são freqüentemente tratados por pesquisadores do consumidor, sendo principalmente de natureza avaliativa, isto é, eles capturam uma avaliação direta ou global de um indivíduo de uma atitude mostrada como favorável ou desfavorável.

Por fim, o componente comportamento é a intenção do consumidor a agir de forma positiva, negativa ou neutra em relação a uma marca, produto ou serviço que se baseia na postura de seu componente afetivo. $O$ último componente do modelo de atitude está preocupado com a máxima verossimilhança ou a tendência de o indivíduo realizar uma ação específica ou se comportar de uma maneira particular no que diz respeito à atitude (SCHIFFMAN, KANUK, 2000).

\subsubsection{Atitude em relação ao anúncio}

A atitude em relação ao anúncio pode ser definida como uma predisposição por parte do consumidor em responder, de forma favorável ou desfavorável, a um determinado estímulo de comunicação durante uma determinada ocasião de exposição (SOLOMON, 2002). De acordo com Blackwell, Engel e Miniard (2005), a eficiência da propaganda em criar atitudes positivas em relação a um produto ou marca vai depender, normalmente, das atitudes dos consumidores em relação ao próprio anúncio. Segundo Schiffman e Kanuk (2000), no momento em que o indivíduo é exposto à propaganda, ele forma diversos sentimentos e julgamentos que afetam sua atitude frente à propaganda. 
São diversos os fatores que determinam a atitude em relação a propaganda, tais como: o anunciante, a qualidade do anúncio, o estado de espírito evocado pelo anúncio e os níveis de envolvimento do consumidor (BLACKWELL, ENGEL e MINIARD, 2005).

Conforme Pereira e Ayrosa (2004), os sentimentos transmitidos por um anúncio não só podem influenciar as atitudes em relação ao anúncio em si, como também podem afetar as atitudes em relação à marca; logo um consumidor exposto a um anúncio ou embalagem de um produto pode demonstrar uma atitude neutra em relação ao anúncio, mas se sentir envolvido por algum apelo contido, como, por exemplo, um apelo ecológico na mensagem, poderá, desta maneira, apresentar uma melhor avaliação em relação à marca ou produto.

A atitude em relação ao anúncio é uma importante conexão entre as percepções dos atributos e as intenções de compra. Segundo Blackwell, Engel e Miniard (2005), um estudo realizado pela Advertising Research Foundation indicou que a opinião dos espectadores sobre um comercial de TV é um importante previsor do sucesso da eficiência do anúncio no mercado. Deste modo, a atitude em relação à propaganda é uma importante variável a ser estudada na comunicação de marketing.

\subsubsection{Intenção de compra}

As intenções são julgamentos subjetivos sobre como será o nosso comportamento no futuro. Existem muitos tipos de intenções comportamentais, e uma delas é a intenção de compra. A intençao de compra representa o que pensamos que vamos comprar (BLACKWELL, ENGEL e MINIARD, 2005).

As pessoas geralmente fazem o que elas tem a intenção de fazer, por isso as intenções tem sido um significante instrumento para prever como as pessoas irão se comportar. No entanto, de acordo com Backwell, Engel e Miniard (2005), embora as intenções de compra sejam um significante previsor de comportamentos, elas estão linge de ser um previsor perfeito. Segundo os autores, as intenções podem mudar e 
circunstâncias inesperadas podem causar essa mudança. Mas apesar dessas limitações, as intenções de compra dos consumidores ainda podem ser a melhor aposta para que as empresas prevejam o comportamento de seus clientes.

\subsection{Hipóteses}

De acordo com Olson e Jacoby (1972), produtos e marcas possuem uma gama de pistas (preço, nome da marca, embalagem, cor, etc.). As informações relativas aos produtos, ou seja, as pistas disponíveis devem, a princípio, gerar respostas (atitudes e comportamento) dos consumidores. Por isso, estas pistas fornecem uma base para o desenvolvimento de diversas impressões sobre o produto. Tomando por base que argumentos ecológicos levam a atitudes favoráveis e preferência por parte do consumidor (OTTMAN, 1994) e considerando que um argumento ecológico é transmitido por estímulo de marketing, no caso, a embalagem do produto, ele pode afetar atitudes relativas à própria embalagem e à intenção de compra (MINIARD, BATHALA e ROSE, 1990). Desta forma as seguintes hipóteses foram formuladas:

Hipótese nula (H0): A atitude e a intenção de compra dos estudantes que receberam os questionários com a embalagem do xampu com o atributo ecológico será indiferente aos que receberam a imagem sem o atributo ecológico.

Hipótese alternativa $(\mathrm{H} 1)$ : Comparando com os estudantes que receberam informações neutras, os estudantes que receberam informações com argumento ecológico:

- H1a: demonstram atitude mais favorável em relação à embalagem.

- H1b: demonstram atitude mais favorável em relação à intenção de compra.

Sendo o argumento ecológico considerado neste estudo um atributo extrínseco do produto, foi inserida na pesquisa a mesma embalagem, sem o atributo ecológico. 


\section{PROCEDIMENTOS METODOLÓGICOS}

\subsection{Delineamento da pesquisa}

Os respondentes foram aleatoriamente divididos em dois grupos. Os dois grupos foram expostos fundamentalmente à mesma imagem. Em um dos grupos a imagem ostentava um argumento ecológico (tratamento 1), o segundo grupo foi exposto à mesma imagem, mas sem o tratamento (tratamento 2), conforme exposto na figura 01.

O argumento ecológico utilizado nesta pesquisa foram os selos "Cosmetique Bio - Charte Cosmebio" e "Ecocert", que dizem respeito a selos de certificação de reconhecimento mundial referente a cosméticos e produtos em geral, que confirma que o produto foi fabricado de maneira ecologicamente correta, utilizando matéria prima, em sua maioria, natural de maneira sustentável e limpa.

Adicionalmente, foram feitas medidas de consciência ecológica, não apenas para explorar o tema, mas também porque podemos relacionar a consciência ecológica dos estudantes com suas atitudes e intenções de compra. Foi utilizada a escala desenvolvida por Straugham e Roberts (1999) traduzida para o português por Lages e Neto (2002).

Foi elaborado um questionário utilizando uma escala para medir a atitude em relação ao anúncio foi uma escala com três perguntas, tipo Likert de sete pontos: Não gostei muito (1) / Gostei muito (7); Nada positivo (1) / Muito positivo (7); para atitudes relativas à embalagem Kamp and Macinnis. Para medir a intenção de compra dos consumidores, foi utilizada a escala de Kilbourne (1986), Painton and Ridley (1985), com três perguntas em escalas de sete pontos: Definitivamente não (1) / Definitivamente sim (7).

A avaliação total do produto foi computada como a soma total dos resultados de cada uma das três escalas de atitude e de intenção de compra. Desta forma, o escore de atitudes e intenção de compra é uma medida que varia entre 3 e 21 .

As variáveis foram definidas considerando como a variável independente a presença/ausência de argumento ecológico, e como variáveis dependentes a atitude 
em relação ao anúncio e a intenção de compra. Para relacionar essas variáveis a metodologia escolhida e mais apropriada foi a experimental (PEDHAZUR; SCHMELKIN, 1991). No caso, esse experimento foi conduzido para analisar a reação dos consumidores em relação a uma embalagem de um cosmético com dois níveis de manipulação (presença de argumento ecológico e ausência de argumento ecológico). O produto usado no experimento foi um xampu da marca OX (vide figura 01).

Figura 1: Estímulos utilizados no experimento

\section{Tratamento 1}

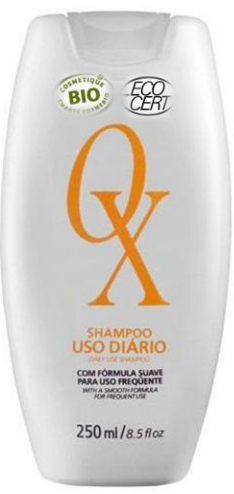

Tratamento 2

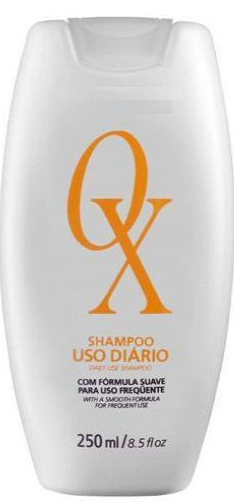

Fonte: Elaborado pelos autores.

O experimento foi conduzido com 100 estudantes de graduação de uma instituição de ensino superior, localizada na cidade do Rio de Janeiro. Cada um dos grupos experimentais foi submetido a um e apenas um tratamento, totalizando 50 questionários no tratamento "com argumento ecológico" e 50 no tratamento "sem argumento ecológico". Durante a execução do experimento, os sujeitos da pesquisa foram aleatoriamente divididos em dois grupos: ao primeiro grupo foi apresentada a imagem de uma embalagem de xampu com o argumento ecológico - dois selos de certificação natural "Cosmetique Bio - Charte Cosmebio" e "Ecocert". Ao segundo grupo foi mostrada a mesma imagem, porém sem a presença do argumento ecológico. 
Após receber os questionários os respondentes preencheram a primeira página que continha pergunta sobre dados pessoais do respondente. Foi utilizado o Critério de Classificação Econômica Brasil para medir o perfil da amostra. Em seguida foram orientados a ler a primeira página e foram autorizados a examinar a imagem, que estava reproduzida na segunda página, por 60 segundos. Finalmente os respondentes foram autorizados a responder o restante do questionário sem poder voltar a visualizar a imagem. A execução deste procedimento durou um período médio de 10 minutos.

A embalagem utilizada está presente no mercado, sua distribuição é intensa e trata-se de uma marca amplamente conhecida de cosméticos, que apresenta preços mais elevados. Além disso, o argumento ecológico usado não está presente na embalagem real comercializada. O selo ecológico foi colocado na embalagem com ajuda de um programa de manipulação gráfica. Após examinarem a imagem da embalagem, os respondentes preencheram um questionário com as medidas das variáveis dependentes e independentes. Este questionário foi elaborado para medir as atitudes dos consumidores em relação ao anúncio e à intenção de compra. Vale ressaltar que também foi inserida no questionário uma escala desenvolvida por Straugham \& Roberts (1999) traduzida para o português por Lages e Neto (2002). A utilização desta escala teve o objetivo de relacionar a variável estranha "consciência ecológica" com a atitude e a intenção de compra dos consumidores.

\subsection{Tratamento dos dados}

Os dados obtidos com os questionários aplicados no experimento foram tabulados e armazenados no Excel, possibilitando a análise estatística dos resultados da pesquisa. Com o objetivo de testar as hipóteses H0, H1a e H1b do estudo, foi conduzida uma análise de variância (ANOVA) para, em seguida, ser realizado o teste $\mathrm{F}$ e comparar as médias das variáveis independentes nos dois tratamentos. Ou seja, analisar o escore das médias das atitudes em relação à 
Revista das Faculdades Integradas Vianna Júnior

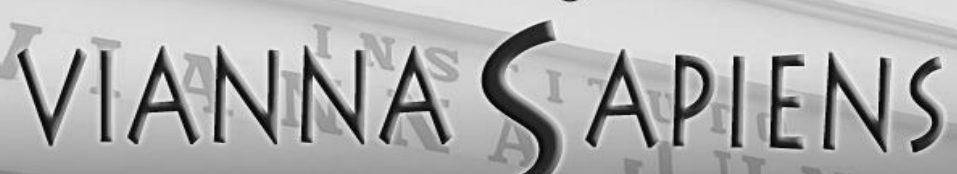

edição especial

Juiz de Fora - 2014

embalagem e a intenção de compra entre o tratamento com a presença do argumento ecológico e o tratamento sem a presença do argumento ecológico.

O método escolhido pode apresentar algumas dificuldades no que diz respeito à coleta e tratamento de dados. A amostra da população é um pouco restrita, pois abrange, em sua grande maioria, faixas etárias entre 18 e 35 anos, e investiga apenas consumidores do Estado do Rio de Janeiro, o que pode limitar a pesquisa e a generalização da mesma. Além deste, grande parte da amostra (86\%) pertence às classes A e B que representam apenas $20 \%$ da população brasileira. Outro ponto seria o alto grau de escolaridade, que pode influenciar uma maior consciência das conseqüências ambientais do ato de consumir.

\section{ANÁLISE E DISCUSSÃO DOS DADOS}

Nessa seção é feita a análise estatística dos dados obtidos através dos questionários aplicados no experimento, assim como a discussão dos resultados. Para cada hipótese deste trabalho foi realizado um teste comparativo entre a média dos escores das variáveis independentes entre os tratamentos. Além deste procedimento estatístico, também foram realizadas análise do perfil da amostra e uma análise de regressão (ANOVA). Desta maneira, a análise dos dados ficou dividida em dois grupos: teste de hipóteses e análise de regressão.

\subsection{Teste de hipóteses}

O teste que realizado para diferença de média de duas amostras possuí três premissas: são amostras independentes; possuem uma distribuição normal e possuem mesma variância. A lógica da análise do teste $F$ é de que a hipótese nula (Ho) é de que as variâncias são iguais, logo se o valor de $P$ for maior que alfa $(0,05)$, não rejeitou a H0, ou seja, as variâncias são iguais. Garantida esta premissa, faz-se o teste da diferença das médias. Neste teste, HO significa que as amostras possuem médias iguais, e H1 significa que as amostras possuem médias diferentes, no caso, 
Revista das Faculdades Integradas Vianna Júnior

\section{VIANNA SAPIENS}

edição especial

Juiz de Fora - 2014

a amostra que recebeu a imagem com o atributo ecológico deveria possuir média maior que a amostra que não recebeu o tratamento. Assim, se o valor $\mathrm{P}$ do teste for superior ao alfa $(0,05)$, não rejeitamos a HO - ou seja, as médias são iguais.

\subsection{Efeito do argumento ecológico sobre as atitudes e a intenção de compra}

As duas primeiras hipóteses prevêem que sujeitos que foram expostos ao argumento ecológico demonstram atitude mais favorável em relação à embalagem (H1a) e intenção de compra mais favorável (H1b), que aqueles que não foram expostos ao argumento ecológico.

Foi conduzida uma análise de variância (ANOVA) com o objetivo de comparar as médias entre os escores das variáveis dependentes entre os tratamentos dos sujeitos expostos ao argumento ecológico dos que não foram expostos ao argumento ecológico. As médias das variáveis dependentes do estudo em cada tratamento e as referidas variâncias são apresentadas na tabela da ANOVA.

Tabela 1: Atitude Frente a Embalagem

\begin{tabular}{lllll}
\hline Grupo & Contagem & Soma & Media & Variância \\
\hline Atitude sem atributo & 50 & 518 & 10,36 & 9,745306 \\
ecológico & & & & \\
\hline Atitude com atributo & 50 & 571 & 11,42 & 9,268898 \\
ecológico & & & & \\
\hline
\end{tabular}

Anova

\begin{tabular}{lllllll}
\hline Fonte de Variação & SQ & gl & MQ & F calculado & Valor-p & F Critico \\
\hline Entre grupos & 28,09 & 1 & 28,09 & 2,95621 & 0,09978 & 3,938111 \\
\hline Dentro dos grupos & 931,7 & 98 & 9,507142 & & & \\
\hline Total & 959,79 & 99 & & & & \\
\hline
\end{tabular}

Como $\mathrm{F}$ calculado < F crítico, não rejeito $\mathrm{HO}$

Como valor-p $(0,08879)>\alpha(0,05)$ Não rejeitamos $\mathrm{H} 0$. 
Revista das Faculdades Integradas Vianna Júnior

\section{VIANNA SAPIENS}

Tabela 2: Intenção de compra

\begin{tabular}{|c|c|c|c|c|c|}
\hline Grupo & & Contagem & Soma & Media & Variância \\
\hline $\begin{array}{l}\text { Atitude } \\
\text { ecológico }\end{array}$ & sem atributo & 50 & 491 & 9,82 & 15,8649 \\
\hline $\begin{array}{l}\text { Atitude } \\
\text { ecológico }\end{array}$ & com atributo & 50 & 490 & 9,80 & 13,67347 \\
\hline
\end{tabular}

Anova

\begin{tabular}{lllllll}
\hline Fonte de Variação & SQ & gl & MQ & F calculado & Valor-p & F Critico \\
\hline Entre grupos & 0,01 & 1 & 0,01 & 0,000677 & 0,979294 & 3,938111 \\
\hline Dentro dos grupos & 1447,38 & 98 & 14,76918367 & & & \\
\hline Total & 1447,39 & 99 & & & & \\
\hline
\end{tabular}

Como $\mathrm{F}$ calculado < F crítico, não rejeito $\mathrm{H} 0$

Como valor-p $(0,979294)>\alpha(0,05)$ Não rejeitamos H0.

Alem de apresentar a diferença das médias entre os tratamentos os resultados da ANOVA (ver tabela 01) mostram que não foi encontrada uma diferença significativa entre as médias da atitude em relação à embalagem entre os tratamentos. Logo, não é possível rejeitar a hipótese nula e a hipótese H1a não é confirmada. Desta forma, não foi verificada uma diferença significativa entre as médias das atitudes dos consumidores entre os que foram expostos ao tratamento com argumento ecológico e os que foram expostos a embalagem sem o argumento ecológico.

A hipótese $\mathrm{H} 1 \mathrm{~b}$ afirma que comparando com os sujeitos que receberam informações neutras, os sujeitos que receberam informações com argumento ecológico demonstram atitude mais favorável em relação à intenção de compra. Através da análise da ANOVA verificamos que não existe uma diferença significativa entre as médias relativas à intenção de compra, entre os sujeitos expostos ao argumento ecológico e os do grupo de controle. Desta forma não foi possível rejeitar 
a hipótese nula $(\mathrm{H} 0)$ e conseqüentemente não foi confirmada a hipótese $\mathrm{H} 1 \mathrm{~b}$. Este resultado sugere que os consumidores não demonstram intenção mais favorável de compra na presença de um apelo ecológico na embalagem do xampu.

\subsection{Relação da atitude e intenção com consciência ecológica (ce)}

Ao analisarmos as respostas dos questionários, no quesito consciência ecológica, percebemos que a maioria dos respondentes possuem um alto grau de consciência ecológica, no entanto, estes mesmos consumidores parecem não relacionar a orientação ecológica do produto em questão com a sua atitude e intenção de compra. Talvez os consumidores necessitem de informações mais claras e objetivas sobre o processo como determinado produto foi produzido e se foi de uma forma ecologicamente correta.

\section{CONSIDERAÇÕES FINAIS}

Observamos neste estudo que comparando as atitudes e a intenção de compra dos consumidores que receberam a imagem com o argumento ecológico aos dos que receberam a mesma imagem sem nenhum tratamento não houve diferenças significativas na média das atitudes em relação a embalagem e a intenção de compra do cosmético. Logo, as hipóteses H1a e H1b não foram confirmadas, pois a diferença entre os dois tratamentos teve pouca significância.

Podemos inclusive, comparar esse resultado com o de Pereira (2004), Lages e Neto (2002) e Velter, Battistella, Grohmann, Castro, Costa e Hermann (2009), que confirmam em suas pesquisas que não é possível afirmar que a presença de apelos ecológicos nas embalagens dos produtos afeta a atitude e a intenção de compra do consumidor brasileiro.

No presente estudo, sugerimos que a presença de argumentos ecológicos em cosméticos não afetam a intenção de compra e a atitude frente ao anúncio do 
Revista das Faculdades Integradas Vianna Júnior

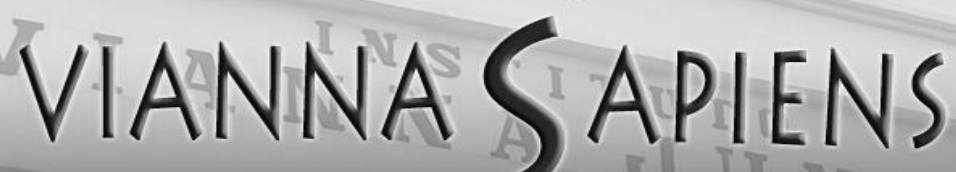

edição especial

produto, pois os consumidores parecem não ter avaliado melhor a embalagem com o argumento ecológico. Isso tenha ocorrido talvez, por os consumidores terem se mostrado céticos em relação à embalagem e não especificamente ao atributo ecológico.

Outro fator que pode explicar essa aparente indiferença dos consumidores em relação à embalagem que contém o apelo ecológico seria pela falta de informação dos consumidores em geral. Uma vez que o anúncio ou a embalagem não fornecem informações relevantes ou específicas, ele não terá influência na formação de opinião do consumidor (MINIARD, BLACKWELL e ENGEL, 2005).

Podemos dizer então, que os consumidores carecem de mais informações sobre tais selos ecológicos presentes nos cosméticos naturais e nos produtos em geral. A falta de clareza e esclarecimento por parte dos consumidores em relação a tais certificações pode afetar sua capacidade de avaliação e confiança sobre as informações contidas nos produtos.

Além disso, a partir da análise dos dados sobre consciência ecológica percebemos que os consumidores possuem um alto grau de consciência ecológica, no entanto verificou-se que estes possuem baixa atitude em relação à embalagem e baixa intenção de comprar o produto. Dessa forma, podemos afirmar que ainda que os consumidores apresentem alto grau de consciência ecológica, ele ainda não aplica tal comportamento na hora da compra de cosméticos.

Nota-se também, que apesar dos consumidores terem consciência ambiental, eles ainda não demonstram ter consciência de que estes problemas podem estar diretamente relacionados às suas atitudes de consumo.

Por isso, as empresas de cosméticos devem continuar fazendo uso do marketing verde, assim como as ações de marketing da Natura e O Boticário que surtiram efeitos positivos na mente dos consumidores, e focar em sua comunicação o esclarecimento, fornecendo informações claras sobre seus produtos, para que elas de fato sirvam como um diferencial na percepção de seus clientes.

Dessa forma, essa pesquisa se faz importante tanto para o meio acadêmico como também para o meio empresarial, pois vemos que a sustentabilidade nas 
Revista das Faculdades Integradas Vianna Júnior

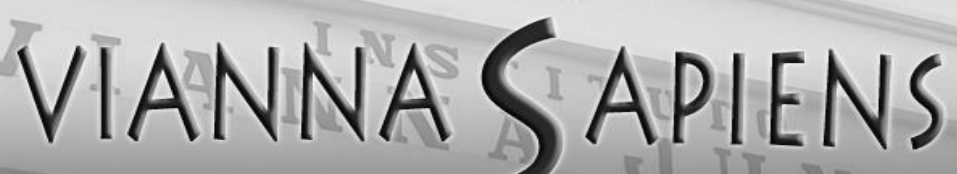

edição especial

uiz de Fora - 2014

empresas pode representar um vasto campo de oportunidades para as práticas do marketing. Essa ferramenta deve ser utilizada com mais intensidade, promovendo práticas nobres, como a produção e comercialização de produtos e serviços que convivam harmonicamente com o meio ambiente.

Diante disso, o desafio que se apresenta se refere ao desenvolvimento e à utilização de mecanismos mercadológicos que assegurem a veracidade dos conteúdos veiculados nas embalagens e propagandas de cosméticos, de forma a aumentar a credibilidade dos consumidores frente aos apelos ecológicos utilizados. Por fim, considera-se que o presente trabalho abre oportunidades para uma série de estudos futuros, principalmente devido ao pouco conhecimento e exploração do conteúdo.

\section{AN EXPERIMENT ON INTENTION TO PURCHASE THE PACKAGE FRONT AND ATTITUDE OF CONSUMERS WITH ECOLOGICAL COSMETICS CERTIFICATION}

ABSTRACT

The present study aims to address the issue as environmental marketing strategy for the marketing of eco-friendly cosmetics, as well as propose and test a statistical model to analyze the effects of environmental marketing strategies on attitudes and purchase intent of consumers. For this, we investigate the impact of an argument on the ecological character attitudes to packaging and purchase intent. Data were collected through an experimental study with 100 undergraduate students in Rio de Janeiro. By completing the experiment, it was found that the respondents proved to be indifferent to the presence of ecological arguments regarding packaging and purchase intent. We can say that this research is relevant to provide the academic community, professional and businesses a better understanding of consumer 


\section{Revista das Faculdades Integradas Vianna Júnior}

\section{VIANNA \\ APIENS}

edição especial

Juiz de Fora - 2014

attitudes

towards

environmental

appeals

in

cosmetics.

KEYWORDS: ECOLOGICAL ATTRIBUTE. ENVIRONMENTAL MARKETING. ATTITUDE TOWARDS ADVERTISING. PURCHASE INTENT.

\section{REFERÊNCIAS}

ALVES, S. R. de A. Comunicação em Marketing Ambiental: características e necessidade de especialização, [Dissertação de Mestrado]. Universidade do Minho. Escola de Engenharia. Portugal, 2005.

ASSOCIAÇÃO BRASILEIRA DA INDÚSTRIA DE HIGIENE PESSOAL, PERFUMARIA E COSMÉTICOS - ABIHPEC. Disponível em:

http://www.abihpec.org.br Acesso em: 07 de outubro de 2010.

BORELLI, F. C.; HEMAIS, M. W.; DIAS, P. I. R. C. Ecológicos ou controlados? Construindo discursivamente o consumidor consciente. Revista Brasileira de Marketing, v.11, n.2, p. 18-42, 2012.

BURKE, L.; LODGSON, J. M. How corporate social responsibility pays off. Long Range Planning, v.29, n. 4, p.495-502, 1996.

CUPERSCHMIDT, N. R. M.; TAVARES, M. C. Atitudes Em Relação ao Meio Ambiente e Sua Influência no Processo de Compra de Alimentos. In: Enanpad, XXANPAD, 2001.

DE TONI, D.; LARENTIS, F.; MATTA, A. Consumo consciente, valor e lealdade em produtos ecologicamente corretos. Revista de Administração FACES Journal, v.11, n.3, p.136-156, 2012.

DELLINGHAUSEN, C. N.; MONDO, T. S.; COSTA, J. I. P. Beleza em 140 caracteres: um estudo sobre o comportamento do consumidor de cosméticos brasileiros no Twitter. Revista de Negócios, v.17, n.1, p.60-81, 2012.

DIAS, R. Marketing Ambiental: Ética, Responsabilidade Social e Competitividade nos Negócios. São Paulo: Editora Atlas, 2006.

DINATO, M. R.. O comportamento ambiental do consumidor de Porto Alegre. In: Engema, 5, Anais... São Paulo, 1998. 


\section{Revista das Faculdades Integradas Vianna Júnior}

\section{VIANNA SAPIENS}

edição especial

Juiz de Fora - 2014

ENGEL, J. F.; BLACKWELL, R. D. ; MINIARD, P. W. Comportamento do Consumidor. Rio de Janeiro:Ed. ETC, 2005.

ETHOS. Indicadores Ethos de Responsabilidade Social. Disponível em: http://www.ethos.org.br/docs/conceitos_praticas/indicadores/resultados. Acesso em 17 de setembro de 2010.

KELLER, K. L. Strategic Brand Management. Upper Saddle River: Prentice Hall, 1993.

KOTLER, P. Administração de Marketing. 12 ed. São Paulo: Pearson, 2000.

LAGES, N.; NETO, A. V. Mensurando a consciência ecológica do consumidor: um estudo realizado na cidade de Porto Alegre. In: Enanpad, 26, Salvador, Anais... Salvador, 2002.

LYRIO, E. S.; FERREIRA, G. G.; ZUQUI, S. N.; SILVA, A. G. Recursos naturais em biocosméticos: conceito inovador de beleza, saúde e sustentabilidade. Natureza on line, v.9, n.1, p.47-51, 2011.

MACEDO, M. A. S.; CÍPOLA, F. C.; FERREIRA, A. F. R. Análise do desempenho organizacional sob as perspectivas socioambiental e de imagem corporativa: um estudo apoiado em DEA sobre os seis maiores bancos do Brasil. Revista de Gestão, v.12, p.1-16, 2008.

MACKENZIE, S. B.; LUTZ, R. J.; BELCH, G. E. The role of attitude toward the ad as a mediator of advertising effectiveness: a test of competing explanations. Journal of Marketing Research, v.23, p.130-143, 1986.

MINIARD, P. W.; BHATLAH, S.; ROSE, R. L. On the formation ad relationship os ad and brand attitudes: an experimental and causal analysis. Journal of Marketing Research, v.27, p.290-303, 1990.

MCWILLIAMS, A.; SIEGEL, D. S. Corporate Social Responsibility: Strategic Implications. Journal of Management Studies, v.43, p.1-18, 2006.

NEVES, J. A. D.; LIMA, V. S.; PESSOA, R. W. A. Avaliação das ações de responsabilidade social sob a perspectiva dos consumidores de supermercados. Alcance, v.18, n.1, p.108-117, 2011.

OLSON, J. C.; JACOBY, J. Cue Utilization in the Quality Perception Process.

Advances in Consumer Research, 1972.

OTTMAN, J. A. Marketing verde: Desafios e Oportunidades para a nova era do marketing. São Paulo: Makron Books, 1994. 
Revista das Faculdades Integradas Vianna Júnior

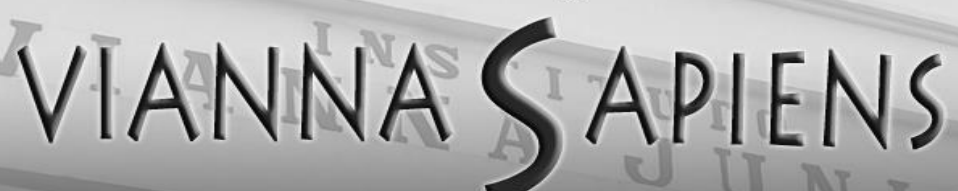

edição especial

PEATTIE, K. Environmental Marketing Management: Meeting the Green

Challenge. London: Pitman Publishing, 1995.

PEDHAZUR, E. J.; SCHMELKIN, L. P. Measurement, Design, and Analysis: an Integrated Approach. New Jersey: LEA, 1991.

PEREIRA, S. J. N.; AYROSA, E. A. T. Atitudes relativas a marcas e argumentos ecológicos: um estudo experimental. Gestão.Org, v.2, n.2, p. 47-55, 2004.

PESSOA, R. W. A.; NASCIMENTO, L. F.; NEVES, J. A. D.; OLIVEIRA FILHO, G. S. Estratégia e vantagem competitiva da reponsabilidade social empresarial. Gestão \& Regionalidade, v.25, n.74, p.79-93, 2009.

RASERA, I. B.; CORRÊA, D. A.; SANTOS, M. R.; OSWALDO, Y. C.

Responsabilidade social corporativa sucroalcooleiro: um estudo sobre percepções das externalidades junto ao público externo. Revista de Administração da Unimep, v. 10, n.3, p.162-182, 2012.

SAUERBRONN, F. F; SAUERBRONN, J. F. R. Estratégias de responsabilidade social e esfera pública: um debate sobre stakeholders e dimensões sociopolíticas de ações empresariais. Revista de Administração Pública, v45, n.2, p.435-458, 2011.

SCHIFFMAN, Leon G.; KANUK, Leslie L. Comportamento do consumidor. Rio de Janeiro: Editora LTC, 2000.

SHETH, J. N.; MITTAL, B.; NEWMAN, B. I. Comportamento do cliente: indo além do comportamento do consumidor. São Paulo: Atlas, 2001.

SOLOMON, M. R. Consumer Behavior: Buying, Having and Being. New Jersey: Prentice-Hall, 2002.

STRAUGHAN, R. D.; ROBERTS, J. Environmental segmentation alternatives: a look at green consumer behavior in the new millennium. Journal of Consumer Marketing, v. 16, n.6, p.558-575, 1999.

SZYBILO, G. J.; JACOBY, J. Intrinsic versus extrinsic cues as determinants of perceived product quality. Journal of Applied Psychology, v.59, p.74-78, 1974.

TAMASHIRO, H. R. S.; MERLO, E. M.; SILVEIRA, J. A. G. Comportamento do consumidor e os atributos que sinalizam as preferências dos formatos de varejo no setor de higiene pessoal, perfumaria e cosméticos. Revista Brasileira de Marketing, v.10, n.2, p.54-83, 2011.

VELTER, A. N.; BATTISTELLA, L. F.; GROHMANN, M. Z.; CASTRO, A. E.; COSTA, V. F.; HERMANN, R. E.; Atitudes dos consumidores a partir da teoria das pistas e da 
Revista das Faculdades Integradas Vianna Júnior

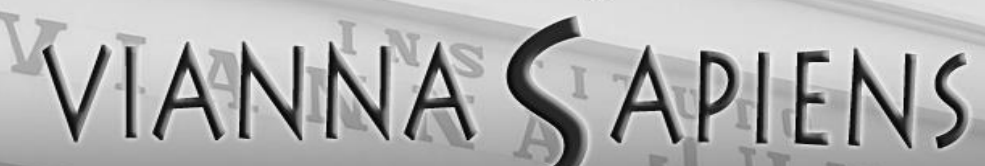

consciência ambiental: Contribuições ao estudo do Green Marketing. Revista de Administração da UFSM, v.2, n.3, p 300-416, 2009.

VOLTOLINI, Ricardo. Marketing ambiental: o consumidor verde influenciando a mudança de práticas mercadológicas nas empresas. In: JUNIOR, A.; DEMAJOROVIC, J. (Org). Modelos e Ferramentas de Gestão Ambiental: desafios e perspectivas para as organizações. São Paulo: Editora SENAC, 2005. 